\title{
The interest cost calculation under IAS 19 when discounting with a yield curve
}

Gennaro Olivieri

Professor of Financial Mathematics at LUISS "Guido Carli”

Actuary - Chartered Accountant - Auditor

Department of Economics (Impresa e Management), Rome (Italy)

\author{
Paola Fersini (Corresponding author) \\ Adjunct Professor of Financial Mathematics (CP) at LUISS “Guido Carli” \\ Chartered Accountant - Auditor, Department of Economics (Impresa e Management) \\ LUISS Guido Carli, Viale Romania, 32 - 00197 Rome (Italy) \\ Tel: +39347 1982137 - email: pfersini@luiss.it
}

Accepted: September 28, 2014

DOI: 10.5296/ijafr.v4i2.6263 URL: http://dx.doi.org/10.5296/ ijafr.v4i2.6263

\begin{abstract}
Some concerns have been raised in recent discussions on how to calculate the interest cost when measuring the defined benefit obligation (DBO) using a yield curve. This article presents the application of some noted concepts on the yield curve in reference to IAS 19.

The issue we investigate specifically concerns the rate or rates to be used when discounting expected liabilities (DBO calculation) and the resulting interest cost (IC) calculation criteria.

We analyze three different approaches that are commonly used in actuarial practice.

These different methods do not produce significant effects on the amount of DBO, while they lead to annual IC values (and consequently actuarial gains/losses) that may be significantly different in relation to the performance of the yield curve.

In this paper, after having reviewed the basic concepts of using a yield curve to evaluate a liability, these concepts are applied to a tangible example in order to quantify the differences that occur in the use of the three approaches. We then show that only the first approach has the characteristics of a model consistent with the assumptions underlying the construction of the model itself.
\end{abstract}

Keywords: International accounting standard 19; Defined benefit obligation; Interest cost 


\section{Introduction}

In this paper, we show that the IC calculation for the period between two subsequent valuations should be calculated consistently with the way it is assumed the yield curve was created at the balance sheet date preceding the date of attributing the Interest Cost.

To this end, we analyze three different approaches to calculate IC that are commonly used in actuarial practice.

The first approach, which we champion in this work, foresees the adoption of an interest rate curve determined with reference to market yields at the balance sheet date (for example, the yield curve of Zero Coupon Bonds of leading companies, as indicated in paragraph 83 of IAS 19).

Discounting the estimated disbursements in each year, at the balance sheet date, is based on the corresponding spot rate observed at the time of the reporting period for operations with maturities that coincide with the disbursement discount date.

The IC recorded at the reporting date is intended to measure the interest to be credited based on notional investments on the previous valuation date (the end of the previous period or the beginning of the current period). According to Pure Expectations Theory, on which we presume the yield curve used at the reporting date is created, the IC is calculated with the first rate (due in a unit period) of the curve used on the preceding valuation date.

The second approach also foresees the adoption of a yield curve, hence disbursements in each year are discounted based on the corresponding spot rate observed at the balance sheet date for operations with maturity dates that coincide with the disbursement date.

Unlike the first approach, however, the yield curve is not created based on Expectations Theory and therefore the IC is calculated with a rate identified as an 'average' of the spot rates, with different maturities, observable at the time of the preceding valuation.

Finally, the third approach foresees the use of a single rate (flat rate) that reflects estimates in relation to the time and amount of benefit payments; the expected disbursements in each year are then discounted according to this rate. This rate may also be an average of the yield curve rates (as defined in paragraph 83 of IAS 19). The IC is calculated according to the flat rate.

Furthermore, in this work, we do not address the problem of estimating stochastic yield curves at subsequent balance sheet dates according to which the DBO and IC will be calculated at these maturity dates, since in the valuation of liabilities in accordance with IAS 19 , at a balance sheet date such subsequent yield curves do not apply.

As mentioned above, and as will be shown in this work, the differences in amounts between the various formulations can even be significant. The explicit solution of this problem is thus functional to the transparency and comparability of actuarial valuations according to the IAS 19 accounting principle.

\section{Present values in the case of constant rates}

As known, the present value V0, at time 0, of a cash flow:

$$
R_{1}, R_{2}, \ldots, R_{n}
$$

with maturities at $1,2, \ldots, \mathrm{n}$, under conditions of certainty and a constant interest rate for the unit period, is given by: 
$V_{0}=\sum_{s=1}^{n} \frac{R_{s}}{(1+i)^{s}}$

Furthermore, the following relation holds:

$V_{0}(1+i)^{n}-\sum_{s=1}^{n} R_{s}(1+i)^{n-s}=0$

and the following recurrent relations apply:

$$
\begin{aligned}
& V_{1}=V_{0}(1+i)-R_{1} \\
& V_{2}=V_{1}(1+i)-R_{2} \\
& " \\
& " \\
& V_{n}=V_{n-1}(1+i)-R_{n}=0
\end{aligned}
$$

Where $\mathrm{V}_{1}, \mathrm{~V}_{2}, \ldots, \mathrm{V}_{\mathrm{n}}$ are the subsequent present values at successive maturities $1,2, \ldots, \mathrm{n}$, of residual cash flow (0) as the $R_{1}, R_{2}, \ldots, R_{n}$ amounts mature.

In this work, among other things, we will derive the corresponding recurrent relationships when using a rate curve to calculate the present value.

\section{Some noted concepts on the yield curve and its use}

A yield curve (for example, the interest rate swap curve in the Euro area) expresses different investment rates according to the duration of the investment. This curve is observed daily on the market (in the financial sense) and expresses, for each period, the synthesis of supply and demand of investments that can be ascribed to this period ${ }^{1}$.

Referring to the following Zero Coupon Bond curve (e.g., derived from bootstrapping the Eurozone swap rate curve)

\footnotetext{
${ }^{1}$ For example, the "ILSW1 Curncy" is a 1 year interest rate swap. This is a plain vanilla interest rate swap on Euribor. Italy $=$ Euro (the rates are the same) and consists of: - Fixed leg (fixed): paid annually, 30/360

- Floating Leg (variable): paid every 6 months, Act/360

The 6-month Euribor rate is fixed 2 working days before the start of the coupon payment period.

For other maturities, similar definitions and compositions apply.

John C. Hull, "Options futures and other derivatives", 7th ed, Pearson Education, page 81:

Business Snapshot 4.1 What is the Risk-Free Rate?

It is natural to assume that the rates on Treasury bills and Treasury bonds are the correct benchmark risk-free rates for derivative traders working for financial institutions. In fact, these derivative traders usually use LIBOR rates as short-term risk-free rates. This is because they regard LIBOR as their opportunity cost of capital (see Section 4.1). Traders argue that Treasury rates are too low to be used as risk-free rates

because: 1 . Treasury bills and Treasury bonds must be purchased by financial institutions to fulfil a variety of regulatory requirements. This increases demand for these Treasury instruments driving the price up and the yield down.

2. The amount of capital a bank is required to hold to support an investment in Treasury bills and bonds is substantially smaller than the capital required to support a similar investment in other instruments with very low risk. 3. In the United States, Treasury instruments are given a favourable tax treatment compared with most other fixed-income investments because they are not taxed at the state level. LIBOR is approximately equal to the short-term borrowing rate of an AA-rated company. It is therefore not a perfect proxy for the risk-free rate. There is a small chance that an AA borrower will default within the life of a LIBOR loan. Nevertheless, traders feel it is the best proxy for them to use. LIBOR rates are quoted out to 12 months. As Chapters 6 and 7 show, the Eurodollar futures market and the swap market are used to extend the trader's proxy for the risk-free rate beyond I 2 months.
} 
$\mathrm{i}(0,4)$

wherein the first variable of rate " $i$ " refers to time 0 when the data is observed and the investment starts, the second variable is the time, expressed for example in number of years, from time 0 when it ends, meaning that on the market, on a certain day (time 0), one-year operations have an annual return equal to the value assumed by $i(0,1)$, those at two years have an annual return equal to the value assumed by $\mathrm{i}(0,2)$, those at three years have an annual return equal to the value assumed by $\mathrm{i}(0,3)$ and those at four years have an annual return equal to the value assumed by $\mathrm{i}(0,4)$.

Having indicated a yield curve:

$i(0, s)$,

with $\mathrm{s}=1,2, \ldots ., \mathrm{n}$, whichever unit periods and 0 the time of reference, the present value of cash flow (0) corresponding to (1) is given by:

$V_{0}=\sum_{s=1}^{n} \frac{R_{s}}{[1+i(0, s)]^{s}}$

According to Pure Expectations Theory, in a perfect and deterministic market, the following relation provides the forward rates for each future period, which can be used as the rates that the market - at the time the current spot yield curve is created - assumes as future spot rates (i.e., the rate curve at each successive maturity t):

$i(t, t+1)=\frac{[1+i(0, t+1)]^{t+1}}{[1+i(0, t)]^{t}}-1$ $t=1,2, \ldots \ldots, n-1$

Therefore:

$[1+i(0, t)]^{t}=\prod_{s=0}^{t-1}[1+i(s, s+1)]$ $t=1,2, \ldots \ldots, n$

Thus (5) can also be written as:

$V_{0}=\sum_{s=1}^{n} \frac{R_{s}}{\prod_{q=0}^{s-1}[1+i(q, q+1)]}$

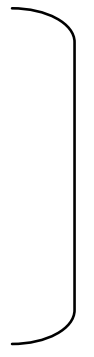

And the relation corresponding with (2), when using a yield curve is:

$V_{0} \cdot \prod_{s=0}^{n-1}[1+i(s, s+1)]-\sum_{s=1}^{n} R_{s} \prod_{q=1}^{n-s}[1+i(s+q-1, s+q)]=0$

We now demonstrate that when using a yield curve the values in (3) are replaced by:

$V_{1}=V_{0}[1+i(0,1)]-R_{1}$

$V_{2}=V_{1}[1+i(1,2)]-R_{2}$

$"$

$V_{n}=V_{n-1}[1+i(n-1, n)]-R_{n}=0$

From (9) we can see that $\mathrm{V}_{1}$, which is the present value at time 1 of the residual cash flow, is 
calculated by capitalizing $\mathrm{V}_{0}$ for a period at rate $\mathrm{i}(0,1)$ and subtracting the amount of $\mathrm{R}_{1}$ already matured. The increase in the recorded value of $\mathrm{V}_{0}$ between time 0 and time 1 , is the interest accruing in that period of time, which in line with the assumptions on the structure of interest rates, is calculated using rate $\mathrm{i}(0,1)$ valid for this period.

From the rates (4), we can derive the implicit forward rate for each future period $1,2, \ldots ., \mathrm{n}-1$, which according to Pure Expectations Theory are equal to the future spot rates for each period.

These rates are given as a function of the rates (4) by:

$i(s, t)=\left\{\begin{array}{ll}{[1+i(0, t)]^{t}} \\ {[1+i(0, s)]^{s}}\end{array}\right\}^{\frac{1}{t-s}}-1 \quad$ for $\begin{aligned} & t=s+1, \ldots ., n\end{aligned}$

Hence, the successive present values at $1,2, \ldots, \mathrm{n}-1$ are given by:

$V_{s}=\sum_{t=s+1}^{n} \frac{R_{t}}{[1+i(s, t)]^{t-s}}$

$s=1,2, \ldots . n-1$

with $\mathrm{V}_{\mathrm{n}}=0$.

This can be written in the following way:

$$
V_{s}=\sum_{t=s+1}^{n} \frac{R_{t}}{\left\{\frac{[1+i(o, t)]^{t}}{[1+i(o, s)]^{s}}\right\}^{\frac{1}{t-s} \cdot(t-s)}} \quad \begin{aligned}
& \\
& s=1,2, \ldots ., n-1
\end{aligned}
$$

From (12) we obtain:

$$
V_{s}=[1+i(0, s)]^{s} \sum_{t=s+1}^{n} \frac{R_{t}}{[1+i(0, t)]^{t}} \quad s=1,2, \ldots, n-1
$$

And finally:

$$
V_{s}=[1+i(0, s)]^{s}\left\{\frac{V_{s-1}}{[1+i(0, s-1)]^{s-1}}-\frac{R_{s}}{[1+i(0, s)]^{s}}\right\}=V_{s-1}[1+i(s-1, s)]-R_{s}
$$$$
s=1,2, \ldots, n-1
$$

which proves (9).

Furthermore, the Interest Cost component $V_{s-1} i(s-1, s)$ can be isolated from the second expression of (14), which in $s=1$ gives the accrued interest between time 0 and time 1 .

There is some doubt, from an actuarial perspective, as to whether the interest calculation (IAS 19 Interest Cost) for the first year can be measured based on rate $\mathrm{i}(0,1)$, as inferred by the first expression of (9), suggesting a calculation according to a different rate which, for example, could be an average of the rates $i(0,1), i(0,2), \ldots, i(0, n)$. 


\section{Macrothink}

International Journal of Accounting and Financial Reporting

ISSN 2162-3082

2014, Vol. 4, No. 2

The yield curve is expressly created for valuations ${ }^{2}$ and does not necessarily express real opportunities or that the actual investment was made at the rates and with the durations indicated in the curve itself. However, to better understand the issue highlighted in this work, let us assume that in the example we are proposing, $\mathrm{n}$ Zero Coupon Bonds have been purchased at respectively $1,2, \ldots, \mathrm{n}$ years, with nominal value:

$R_{1}, R_{2}, \ldots, R_{n}$

Each cost at time 0 of the $n$ bonds, based on the rates $i(0,1), i(0,2), \ldots, i(0, n)$ will be given by:

$$
\frac{R_{s}}{[1+i(0, s)]^{s}}
$$

with $\mathrm{s}=1,2, \ldots, \mathrm{n}$.

Let us therefore assume, taking into account the actual investment, that we want to record the interest that will accrue during the first period, according to the Law of Compound Interest, on $\mathrm{n} \mathrm{ZCBs}^{3}$ :

$$
I_{1}=\sum_{t=1}^{n} \frac{R_{t} i(0, t)}{[1+i(0, t)]^{t}}
$$

in the second year:

$$
I_{2}=\sum_{t=2}^{n} \frac{R_{t} i(0, t)}{[1+i(0, t)]^{t-1}}
$$

and so forth. Generally:

$$
I_{s}=\sum_{t=s}^{n} \frac{R_{t} i(0, t)}{[1+i(0, t)]^{t-s+1}}
$$

with $\mathrm{t}=1,2, \ldots, \mathrm{n}$

Equation (18) implies that independently of the valuation period, each bond of duration $t$ yields interest in each subsequent period at time 0 at the rate $i(0, t)$. Therefore, the one-year bond will accrue interest between time 0 and time 1 at the rate $\mathrm{i}(0,1)$, two-year bonds will accrue interest between time 0 and time 1 at the rate $i(0,2)$ and between time 1 and time 2 at the same rate $\mathrm{i}(0,2)$ and so forth for the other bonds.

Thus, if the interest accrued in the various periods is calculated according to (16), (17) and (18), the value of the residual cash flow after the maturity of the individual amounts related to the cash- flow rate

\footnotetext{
${ }^{2}$ Often, in our view, other types of rates are mistakenly used such as the Iboxx EUR Corporates AA and A that refer to representative bond basket price indices with the same rating and measure their "overall performance". They therefore measure ex post (and not ex ante) rates of return and hence cannot be used for discounting (valuations).

${ }^{3}$ In this case, we want to show that if assets are purchased to cover the commitment and the interest is recorded that accrues according to a normal accounting principle and the market in subsequent periods forms interest rates according to "Pure Expectations Theory", then unexplainable actuarial gains or losses will be generated.
} 
$R_{1}, R_{2}, \ldots, R_{n}$

at the end of each unit period, will be given by:

$W_{s}=\sum_{t=s+1}^{n} \frac{R_{t}}{[1+i(0, t)]^{t-s}}$

with $\mathrm{s}=1,2, \ldots, \mathrm{n}-1$, and with $\mathrm{W}_{\mathrm{n}}=0$ e $\mathrm{W}_{0}=\mathrm{V}_{0}$ given by (5).

Based on Market Expectation Theory, it is evident that the values provided by (19), which uses the rates $\mathrm{i}(0, \mathrm{t})$, do not coincide with the values given by $(11)$, which uses rates $\mathrm{i}(\mathrm{s}, \mathrm{t})$ with $\mathrm{s}=1,2,3 \ldots \mathrm{n}-1$.

If we assume that the yield curves created in subsequent unit periods $1,2, \ldots, n-1$ will correspond to the predictions made at valuation time 0, according to Pure Expectations Theory, the difference between the values of $\mathrm{V}_{\mathrm{s}}$ given by (11) and the values $\mathrm{W}_{\mathrm{s}}$ given by (19) constitute, in the context of IAS 19, unjustifiable actuarial gains or losses. This is because if we use a model and assume that the achievements correspond to that model, then it is clear that gains or losses cannot be due to changing the model or to achievements that differ from the assumptions made at the time of the initial valuation.

We now analyze the generation of actuarial gains or losses.

The difference:

$\mathrm{V}_{1}-\mathrm{W}_{1}$

using (13) for $\mathrm{s}=1$ for $\mathrm{V}_{1}$, we can write:

$[1+i(0,1)] \sum_{t=2}^{n} \frac{R_{t}}{[1+i(0, t)]^{t}}-\sum_{t=2}^{n} \frac{R_{t}}{[1+i(0, t)]^{t-1}}=\sum_{t=2}^{n} \frac{R_{t}[i(0,1)-i(0, t)]}{[1+i(0, t)]^{t}}$

If we add the difference given by (21) to (16):

$\sum_{t=1}^{n} \frac{R_{t} i(0, t)}{[1+i(0, t)]^{t}}+\sum_{t=2}^{n} \frac{R_{t}[i(0,1)-i(0, t)]}{[1+i(0, t)]^{t}}$

with some simple algebra, we obtain:

$i(0,1) \sum_{t=1}^{n} \frac{R_{t}}{[1+i(0, t)]^{t}}$

which is the Interest Cost accrued between time 0 and time 1 (a component that can be isolated in the second expression of (14)).

This shows that if the IC relative to the first unit period is calculated according to the formulation here criticized (calculated according to expression 16), unjustifiable actuarial gains or losses are generated that when added (algebraically) to the IC component (calculated according to 16), result in a net capital movement by an amount exactly equal to the IC calculated according to the formulation that we consider correct.

The value at the end of the second unit period must be derived starting from the market value 
calculated at the end of the previous period:

$W_{2}^{*}=V_{1}+\sum_{t=2}^{n} \frac{R_{t} i(0, t)}{[1+i(0, t)]^{t-1}}-R_{2}$

thus, actuarial gains or losses that will be generated at the end of the second year will be given by the difference:

$\mathrm{V}_{2}-\mathrm{W}_{2}{ }^{*}$

and hence by:

$V_{2}-V_{1}-\sum_{t=2}^{n} \frac{R_{t} i(0, t)}{[1+i(0, t)]^{t-1}}+R_{2}$ 2014, Vol. 4, No. 2

which recalling (14) for $\mathrm{s}=2$, becomes:

$V_{1} i(1,2)-\sum_{t=2}^{n} \frac{R_{t} i(0, t)}{[1+i(0, t)]^{t-1}}$

This added to expression (17) also generates the movement in net capital equal to that obtained from the second expression of (14) for $\mathrm{s}=2$.

In general, the expression of the actuarial gains or losses can be written as:

$V_{s-1} i(s-1, s)-\sum_{t=s}^{n} \frac{R_{t} i(0, t)}{[1+i(0, t)]^{t-s+1}}$

with $\mathrm{s}=1,2, \ldots, \mathrm{n}$

which, added to (18) gives the second expression of (14).

If we add (14) to (28), we again derive the expression:

$V_{s-1} i(s-1, s)$

As an alternative to the IC calculation according to (18), there is another application that foresees the use of the internal rate of return.

In this case, either (5) or (7), which are the same, is replaced by:

$V_{0}=\sum_{s=1}^{n} \frac{R_{s}}{[1+\bar{i}(0, n)]^{s}}$

where:

$\bar{i}(0, n)$

is the IRR that from cash flow:

$R_{1}, R_{2}, \ldots, R_{n}$

generates the same value $\mathrm{V}_{0}$ derived from (5) or from (7).

This rate represents an average, in the sense of Chisini, of rates (4) or (6), in that replacing these rates produces the same present value of cash flows calculated by using the appropriate rates (4) or (6). 


\section{Macrothink}

In this case, the interest in relation to the first period is given by:

$I_{1}^{* *}=V_{0} \bar{i}(0, n)$

and the value at the end of the first period is given by:

$W_{1}^{* *}=V_{0}+I_{1}^{* *}-R_{1}$

which cannot give the same numerical value of (11) inasmuch as in (32) interest is calculated using the rate

$\bar{i}(0, n)$

while adoption of (11) assumes that the interests produced between 0 and 1 is calculated with the rate $\mathrm{i}(0,1)$.

The actuarial gains or losses will be given by:

$\mathrm{V}_{1}-\mathrm{W}_{1}{ }^{* *}$

In $\mathrm{t}=1$, from rates $\mathrm{i}(1,2), \mathrm{i}(1,3), \ldots, \mathrm{i}(1, \mathrm{n})$ we can derive the average rate $\bar{i}(1, n)$, in the sense specified above, namely, calculated as the IRR of an operation that compares value $\mathrm{V}_{1}$ with the remaining cash flow $R_{2}, R_{3}, \ldots . R_{n}$.

The interest for the second period is given by:

$I_{2}^{* *}=V_{1} \bar{i}(1, n)$

and the value at the end of the second period is given by:

$W_{2}^{* *}=V_{1}+I_{2}^{* *}-R_{2}$

Also in this case, $\mathrm{W}_{2}{ }^{* *}$ does not give the same numerical value of (11) inasmuch as in (32) the interest rate is calculated using the rate

$\bar{i}(1, n)$

while adoption of (11) assumes that the interest produced between 1 and 2 is calculated with the rate $\mathrm{i}(1,2)$.

And the actuarial gains or losses will be given by:

$\mathrm{V}_{2}-\mathrm{W}_{2}{ }^{* *}$

and so forth for subsequent values.

Clearly, equality between (11) and (32) can only be achieved using "flat" rates. 


\section{Mll Macrothink}

International Journal of Accounting and Financial Reporting

ISSN 2162-3082

2014, Vol. 4, No. 2

\section{Numerical application}

In order to clarify the theoretical framework, we illustrate a numerical application below that compares the three different approaches to the calculation of the interest cost component and enables quantifying the accounting effects.

We refer to the following Zero Coupon Bond yield curve:

$\mathrm{i}(0,1)=5 \%$
$\mathrm{i}(0,2)=10 \%$
$\mathrm{i}(0,3)=20 \%$
$\mathrm{i}(0,4)=40 \%$

This curve has been created on a given day, according to Pure Expectations Theory, and implies that on that day the market expects that within a year the yield rate of a one-year operation i $(1,2)$ will be $15.238 \%$, while two-year operations in one years' time will have a yield rate $\mathrm{i}(1,3)$ of $28.285 \%$ per year and three-year operations will have a yield rate $\mathrm{i}(1,4)$ of $54.090 \%$ per year ${ }^{5}$.

The market itself, at time 0 , expects that in 2 years' time the yield rate of operations at 1 year $(2,3)$ will be $42.810 \%$, while operations of a two-year duration in two years' time will have a yield rate $i(3,4)$ of $78.182 \%$ per year.

Finally, the market at time 0 expects that in 3 years' time the yield rate of operations at 1 year $(3,4)$ will be $122.315 \%$.

According to Pure Expectations Theory, inherent in the yield curve is that the market perceives a four-year investment at $40 \%$ or 4 annual investments - the first at 5\%, the second at $15.238 \%$, the third at $42.810 \%$, and the fourth at $122.315 \%$ - as equivalent so that arbitrage cannot be implemented at time 0 .

The key assumption in adopting a yield curve, according to Pure Expectations Theory, is that whatever the duration, the hypothetical investments, from the valuation time onwards, could all be invested at 5\% in the first year, could all be invested at $15.238 \%$ in an eventual second year, could all be invested at $42.810 \%$ in an eventual third year and could all be invested at $122.315 \%$ in an eventual fourth year.

Assume you have purchased $4 \mathrm{ZCBs}$, respectively at 1, 2, 3 and 4, each with a nominal value of 1.000 euro.

Under these conditions and assumptions, the present value at time (0) of the cash flow represented by the nominal values of the 4 bonds:

\footnotetext{
${ }^{4}$ The values of the rates are deliberately unrealistic to numerically emphasize the point we want to illustrate.

${ }^{5}$ Bortot, Magnani, Olivieri, Rossi e Torrigiani - Matematica Finanziaria - Seconda Edizione - Monduzzi editore - Bologna 1998 - cap. 1, paragrafo 1.7 e 1.8

F. Cacciafesta - Lezioni di Matematica Finanziaria classica e moderna - G. Giappichelli editore - Torino 2001 - cap. 9
}

See also Fama \& Miller, The Theory of Finance, Dryden Press, Illinois (USA), 1971 
Table 1

is equal to 2617.84 .

\begin{tabular}{|l|l|}
\hline Time & Amount \\
\hline 1 & 1000 \\
\hline 2 & 1000 \\
\hline 3 & 1000 \\
\hline 4 & 1000 \\
\hline
\end{tabular}

At time 1, the present value of the remaining cash flow is equal to 1748.73 , at time 2 the present value of the residual cash flow is equal to 1015.20 and at time 3 it is equal to 449.81 . The interest earned over the course of four years will be:

Table 2

\begin{tabular}{|l|l|}
\hline During the year & Accrued interest \\
\hline 1 & 130.89 \\
\hline 2 & 266.47 \\
\hline 3 & 434.61 \\
\hline 4 & 550.19 \\
\hline
\end{tabular}

which correspond to the value produced at the beginning of each period for the next spot rate valid between $t$ and $t+1$, with $t=0,1, \ldots, 3$, as highlighted in the latter part of (14).

The Table 3 shows the dynamic performance of the interest and values of the 4 bonds:

Table 3

\begin{tabular}{|l|l|l|l|l|l|l|l|l|l|l|l|l|l|}
\cline { 2 - 12 } \multicolumn{1}{l|}{ 1 Bond } & \multicolumn{3}{l|}{ 2nd Bond } & \multicolumn{3}{l|}{ 3rd Bond } & \multicolumn{3}{l|}{ 4th Bond } \\
\hline & Price & Interest & Value & Price & Interest & Value & Price & Interest & Value & Price & Interest & Value \\
\hline 0 & 952.38 & & & 826.45 & & & 578.70 & & & 260.31 & & \\
\hline 1 & & 47.62 & 1000.00 & & 41.32 & 867.77 & & 28.94 & 607.64 & & 13.02 & 273.32 \\
\hline 2 & & & & & 132.23 & 1000.00 & & 92.59 & 700.23 & & 41.65 & 314.97 \\
\hline 3 & & & & & & & & 299.77 & 1000.00 & & 134.84 & 449.81 \\
\hline 4 & & & & & & & & & & & 550.19 & 1000.00 \\
\hline
\end{tabular}

And the summary results:

Table 4

\begin{tabular}{|l|l|l|l|}
\hline & TOT. INTERESTS (I) & TOT. VALUE (V) & Rate (I/V) \\
\hline 0 & & 2617.84 & \\
\hline 1 & 130.89 & 1748.73 & $5.00 \%$ \\
\hline 2 & 266.47 & 1015.20 & $15.24 \%$ \\
\hline 3 & 434.61 & 449.81 & $42.81 \%$ \\
\hline 4 & 550.19 & - & $122.31 \%$ \\
\hline
\end{tabular}

And, therefore, the impact on Net Capital: 
Table 5

\begin{tabular}{|l|l|l|l|l|l|l|l|}
\hline $\begin{array}{l}\text { TIME } \\
(\mathrm{t})\end{array}$ & $\begin{array}{l}\text { Value at } \\
\text { period } \\
\text { start } \\
\left(\mathrm{V}_{\mathrm{t}-1}\right)\end{array}$ & $\begin{array}{l}\text { INTEREST } \\
\left(\mathrm{I}_{\mathrm{t}}\right)\end{array}$ & $\begin{array}{l}\text { REIMBURSEMENT } \\
\left(\mathrm{R}_{\mathrm{t}}\right)\end{array}$ & $\begin{array}{l}\text { FINAL } \\
\text { CAP. } \\
\left(\mathrm{W}_{\mathrm{t}}=\right. \\
\left.\mathrm{V}_{\mathrm{t}-1}+\mathrm{I}_{\mathrm{t}}\right)\end{array}$ & $\begin{array}{l}\text { Value at } \\
\text { period } \\
\text { end }\left(\mathrm{V}_{\mathrm{t}}\right)\end{array}$ & $\begin{array}{l}\text { Act. } \\
(\mathrm{G}) / \mathrm{L} \\
\left(\mathrm{AGL}_{\mathrm{t}}\right. \\
=\mathrm{V}_{\mathrm{t}}- \\
\left.\mathrm{W}_{\mathrm{t}-\mathrm{t}}\right)\end{array}$ & $\begin{array}{l}\text { NC } \\
\text { Impact } \\
\left(\mathrm{NC}_{\mathrm{t}}+\right. \\
\mathrm{I}_{\mathrm{t}}+ \\
\left.\text { AGL }_{\mathrm{t}}\right)\end{array}$ \\
\hline 1 & 2617.84 & 130.89 & 1000.00 & 1748.73 & 1748.73 & - & 130.89 \\
\hline 3 & 1748.73 & 266.47 & 1000.00 & 1015.20 & 1015.20 & - & 266.47 \\
\hline 4 & 1015.20 & 434.61 & 1000.00 & 449.81 & 449.81 & - & 434.61 \\
\hline
\end{tabular}

If we use the same starting data and the same example but carry out the valuation according to the approach described from (15) to (29), we obtain the following results:

Table 6

\begin{tabular}{|l|l|l|l|l|l|l|l|l|l|l|l|l|l|}
\cline { 2 - 12 } \multicolumn{1}{l|}{ 1 Bond } & \multicolumn{3}{l|}{ 2nd Bond } & \multicolumn{3}{l|}{ 3rd Bond } & \multicolumn{3}{l|}{ 4th Bond } \\
\hline & Price & Interest & Value & Price & Interest & Value & Price & Interest & Value & Price & Interest & Value \\
\hline 0 & 952.38 & & & 826.45 & & & 578.70 & & & 260.31 & & \\
\hline 1 & & 47.62 & 1000.00 & & 82.64 & 909.09 & & 115.74 & 694.44 & & 104.12 & 364.43 \\
\hline 2 & & & & & 90.91 & 1000.00 & & 138.89 & 833.33 & & 145.77 & 510.20 \\
\hline 3 & & & & & & & & 166.67 & 1000.00 & & 204.08 & 714.29 \\
\hline 4 & & & & & & & & & & & 285.71 & 1000.00 \\
\hline
\end{tabular}

And the summary results:

Table 7

\begin{tabular}{|l|l|l|l|}
\hline & TOT. INTEREST $(\mathrm{I})$ & TOT. VALUE $(\mathrm{V})$ & RATE $(\mathrm{I} / \mathrm{V})$ \\
\hline 0 & & 2617.84 & \\
\hline 1 & 350.13 & 1967.97 & $13.37 \%$ \\
\hline 2 & 375.57 & 1343.54 & $19.08 \%$ \\
\hline 3 & 370.75 & 714.29 & $27.59 \%$ \\
\hline 4 & 285.71 & - & $40.00 \%$ \\
\hline
\end{tabular}

And finally, the relative impact on Net Capital:

Table 8

\begin{tabular}{|c|c|c|c|c|c|c|c|}
\hline $\begin{array}{l}\text { TIME } \\
\text { (t) }\end{array}$ & $\begin{array}{l}\text { Value at } \\
\text { period } \\
\text { start } \\
\left(\mathrm{V}_{\mathrm{t}-1}\right)\end{array}$ & $\begin{array}{l}\text { INTEREST } \\
\left(\mathrm{I}_{\mathrm{t}}\right)\end{array}$ & $\begin{array}{l}\text { REIMBURSEMENT } \\
\left(\mathrm{R}_{\mathrm{t}}\right)\end{array}$ & $\begin{array}{l}\text { FINAL } \\
\text { CAP. } \\
\left(\mathrm{W}_{\mathrm{t}} \quad=\right. \\
\mathrm{V}_{\mathrm{t}-1} \\
\left.\mathrm{I}_{\mathrm{t}}-\mathrm{R}_{\mathrm{t}}\right)\end{array}$ & $\begin{array}{l}\text { Value at } \\
\text { period } \\
\text { end }\left(V_{t}\right)\end{array}$ & $\begin{array}{l}\text { Act. } \\
(\mathrm{G}) / \mathrm{L} \\
\left(\mathrm{AGL}_{\mathrm{t}}=\right. \\
\left.\mathrm{V}_{\mathrm{t}}-\mathrm{W}_{\mathrm{t}-\mathrm{t}}\right)\end{array}$ & $\begin{array}{l}\mathrm{NC} \\
\text { Impact } \\
\left(\mathrm{NC}_{\mathrm{t}}=\right. \\
\mathrm{I}_{\mathrm{t}}+ \\
\left.\mathrm{AGL}_{\mathrm{t}}\right)^{+}\end{array}$ \\
\hline 1 & 2617.84 & 350.13 & 1000.00 & 1967.97 & 1748.73 & -219.24 & 130.89 \\
\hline 2 & 1748.73 & 375.57 & 1000.00 & \begin{tabular}{|l|l|}
1124.30 \\
\end{tabular} & 1015.20 & -109.10 & 266.47 \\
\hline 3 & 1015.20 & 370.75 & 1000.00 & 385.95 & 449.81 & 63.86 & 434.61 \\
\hline 4 & 449.81 & 285.71 & 1000.00 & -264.47 & - & 264.47 & 550.19 \\
\hline
\end{tabular}

Applying the formulation that foresees the use of the internal rate of return to calculate the Interest Cost, as described from (30) to (36), in the first year the interest is calculated using as 
the average rate the IRR $\bar{i}(0,4)$, in the second year it is calculated using the rate $\bar{i}(1,4)$, in the third year it is calculated using the rate $\bar{i}(2,4)$ and, finally, for the fourth year it is calculated using the rate $\bar{i}(3,4)$

The Table 9 shows the internal rate of return calculated for each year and used to calculate the interest: 
Table 9

\begin{tabular}{|l|l|l|l|l|}
\cline { 2 - 5 } \multicolumn{1}{c|}{} & 1st year & 2nd year & 3rd year & 4th year \\
\hline 0 & -2617.84 & & & \\
\hline 1 & 1000.00 & -1748.73 & & \\
\hline 2 & 1000.00 & 1000.00 & -1015.20 & \\
\hline 3 & 1000.00 & 1000.00 & 1000.00 & -449.81 \\
\hline 4 & 1000.00 & 1000.00 & 1000.00 & 1000.00 \\
\hline IRR & $19.412 \%$ & $32.728 \%$ & $60.048 \%$ & $122.315 \%$ \\
\hline
\end{tabular}

The results in terms of impact on Net Capital are as follows:

Table 10

\begin{tabular}{|c|c|c|c|c|c|c|c|}
\hline $\begin{array}{l}\text { TIM } \\
\text { E (t) }\end{array}$ & $\begin{array}{l}\text { Value at } \\
\text { period } \\
\text { start } \\
\left(\mathrm{V}_{\mathrm{t}-1}\right)\end{array}$ & $\begin{array}{l}\text { INTEREST } \\
\left(\mathrm{I}_{\mathrm{t}}\right)\end{array}$ & $\begin{array}{l}\text { REIMBURSEMENT } \\
\left(\mathrm{R}_{\mathrm{t}}\right)\end{array}$ & $\begin{array}{l}\text { FINAL } \\
\text { CAP. }\left(\mathrm{W}_{\mathrm{t}}\right. \\
=\mathrm{V}_{\mathrm{t}-1}+ \\
\left.\mathrm{I}_{\mathrm{t}}-\mathrm{R}_{\mathrm{t}}\right)\end{array}$ & $\begin{array}{l}\text { Value at } \\
\text { period } \\
\text { end }\left(V_{t}\right)\end{array}$ & $\begin{array}{l}\text { Act. } \\
(\mathrm{G}) / \mathrm{L} \\
\left(\mathrm{AGL}_{\mathrm{t}}=\right. \\
\left.\mathrm{V}_{\mathrm{t}}-\mathrm{W}_{\mathrm{t}-\mathrm{t}}\right)\end{array}$ & $\begin{array}{l}\mathrm{NC} \\
\text { Impact } \\
\left(\mathrm{NC}_{\mathrm{t}}=\right. \\
\mathrm{I}_{\mathrm{t}}+ \\
\left.\mathrm{AGL}_{\mathrm{t}}\right)^{+}\end{array}$ \\
\hline 1 & 2617.84 & 508.18 & 100 & 2126.02 & 1748.73 & -377.29 & 130.89 \\
\hline 2 & 1748.73 & 572.33 & 1000.00 & 1321.06 & 1015.20 & -305.86 & 266.47 \\
\hline 3 & 1015.20 & 609.61 & 1000.00 & 624.81 & 449.81 & -175.00 & 434.61 \\
\hline 4 & 449.81 & 550.19 & 1000.00 & - & - & - & 550.19 \\
\hline
\end{tabular}

Also with this formulation, as in the second approach, the impact on Net Capital coincides with the IC calculated according to the formulation we here argue for. Again, as in the previous example, if the market achievements correspond to the assumptions made (Market Expectation Theory), then no actuarial gains or losses should be generated and, therefore, the impact on equity should correspond to the values recorded in the income statement.

\section{Conclusions}

We reiterate in conclusion that the yield curve, according to Pure Expectations Theory, expresses market expectations at the time of valuation and these expectations, which at that time do not allow arbitrage, consider multi-year operations and single annual operations as equivalent at the rates determined above. Indeed, this is not about actual investments but represents the expectations of financial operators in relation to various economic and financial parameters.

If deeming the use of an average and therefore constant rate more appropriate, an annual operation at the same rate as a long-term operation would not be possible and we would be looking at a "flat" yield curve, namely, not correlated to the duration of the investment.

If at a later time, in particular in a subsequent unit period, the yield curve were not as expected, this would imply that the results differ from the expectations previously expressed. Adopting a yield curve means that an assumption has been made which the market expresses, generically, as it rightly should in valuations without specific assets to hedge, with investment opportunities with rates that are inherent in the curve itself, as shown above. The differences between expectations and results thus represent losses or gains due precisely to results that differ from expectations.

If the market were to express, in subsequent periods to time 0 , exactly the same rates that 


\section{Macrothink}

International Journal of Accounting and Financial Reporting

ISSN 2162-3082

2014, Vol. 4, No. 2

were inherent in the yield curve at time 0 , then the sequence of interest expressed through such a succession would doubtlessly be correct. If this does not occur, then there are losses or gains due to the difference between expectations and results and using an average rate (in the sense described above) does not appropriately change this formulation.

In conclusion, if adopting a yield curve to obtain present values, then the interest cost must be calculated with the subsequent rates inherent in the curve itself because if adopting some "average" rate, in the sense explained above, which could be falsely identified as an acquired rate, then this would not be in line with the assumptions underlying the adoption of a yield curve.

The above-mentioned inconsistency is also clear when adopting, for the subsequent influx of accrued severance payments, the new "average rates" that form on the market, each differing from preceding "investments".

This does not mean that an average rate cannot be adopted for valuations but the valuation rate(s) must correspond to the rate(s) to calculate the interest cost.

The use of a single rate is a different hypothesis to adopting a yield curve, namely, a "flat" curve with all the considerations that arise there from.

In this paper, we have shown that the IC calculation for the period between two subsequent valuations should be calculated consistently with the way in which the liabilities were valued at the end of the previous period. Therefore, if the liabilities are calculated with a yield curve, the interest cost of the period in question must be calculated with a suitable rate (uniquely identified under the assumption that the yield curve is constructed on Market Expectation Theory) and inherent in the curve itself.

\section{References}

John C. Hull, (2009). Options futures and other derivatives, 7th ed., Pearson Education. Bortot, Magnani, Olivieri, Rossi e Torrigiani (1998). Matematica Finanziaria, Seconda Edizione, Monduzzi editore, Bologna.

F. Cacciafesta (2001). Lezioni di Matematica Finanziaria classica e moderna, G. Giappichelli editore, Torino.

Fama, Miller (1971). The theory of finance, Dryden Press, Illinois (USA). 